\title{
Assessment and prevalence of depression in women 45-55 years of age visiting gynecological clinics in Poland
}

\section{Screening for depression among midlife gynecologic patients}

\author{
M. Wojnar ${ }^{1,5}$, W. Dróżdż ${ }^{2}$, A. Araszkiewicz ${ }^{2}$, W. Szymański ${ }^{3}$, D. Nawacka-Pawlaczyk ${ }^{4}$, \\ R. Urbański ${ }^{4}$, and A. M. Hegedus ${ }^{5}$ \\ ${ }^{1}$ Out-patient Department of Psychiatry, Nowowiejski Hospital, Warsaw, Poland \\ ${ }^{2}$ Department of Psychiatry, University Medical School, Bydgoszcz, Poland \\ ${ }^{3}$ Department of Gynecology and Obstetrics, University Medical School, Bydgoszcz, Poland \\ ${ }^{4}$ Servier Polska, Warsaw, Poland \\ ${ }^{5}$ University of Michigan, Department of Psychiatry, Ann Arbor, Michigan, U.S.A.
}

Received December 4, 2003; accepted May 9, 2003

Published online July 3, 2003 (C) Springer-Verlag 2003

\begin{abstract}
Summary
The aims of the Polish survey were to assess efficacy of screening for depression in gynecological practice and to estimate prevalence of depressive disorders in midlife women visiting gynecologists. The study included 2262 female outpatients aged 45-55, who were screened by 120 gynecologists throughout Poland. Patients completed the Beck's Depression Inventory (BDI) and were assessed by gynecologists to verify the presence of symptoms of a current Depressive Episode according to ICD-10 diagnostic criteria. Patients who obtained a score of 12 points or more on the BDI were referred for psychiatric evaluation, including the modified version of Mini International Neuropsychiatric Interview (MINI). The study showed that gynecologists in Poland are able to perform screenings for depression effectively in outpatient settings. Results also suggested that about $19 \%$ of women aged 45 to 55 years visiting gynecologists may suffer from depressive disorders.
\end{abstract}

Keywords: Depression; women; menopause; screening; prevalence.

\section{Introduction}

Depression is among the most frequently encountered psychiatric disorders in medical practice across different specialties, including general medicine, neurology and gynecology. Regardless of severity of symptoms, depressive disorders affect about one-fifth of primary care patients, but approximately half of those cases remain undiagnosed and untreated (Cathebras et al., 1994; Coyne et al., 1994; Sartorius et al., 1993; Sartorius et al., 1996;
Simon and VonKorff, 1995; Ustun and Sartorius, 1995). The lifetime prevalence of depressive disorders in the general population ranges from $5 \%$ to $17 \%$ (Bebbington et al., 1998; Katon, 1987; Kessler et al., 1994; Robins and Rieger, 1991); depression occurs about two times more frequently in women than in men (Steiner and Yonkers, 1998; Stephenson-Cino et al., 1992).

Depression is regarded as a significant problem for women not only in premenstrual or perinatal periods (Bailey and Cohen, 1999; Braverman and Roux, 1978; Cooper and Murray, 1998; Holcomb et al., 1996; Marcus et al., 2003; Steiner, 1992; Steiner, 1998), but also during menopause transition. Symptoms of depression are confirmed by 10 to $30 \%$ of women aged $45-55$ years (Avis et al., 1994; Ballinger, 1990; Porter et al., 1996; Stone and Pearlstein, 1994). Some studies found increased incidence of depression even in the 5 years preceding menopause (Ballinger, 1990; Schmidt et al., 1997). Among women in this phase of life, depression is two times more prevalent in women who report specific complaints or symptoms and attend menopausal clinics than in women who do not seek gynecological consultation (Anderson et al., 1987; Hay et al., 1994; Nicol-Smith, 1996). However, many studies found no clear correlation between menopause and depression or 
argue that clinical symptoms of depression might be triggered or imitated by physiological signs of menopausal transition (Bosworth et al., 2001; Dennerstein et al., 1999; Kaufert et al., 1992; Matthews et al., 1994; Nicol-Smith, 1996; Pearlstein et al., 1997). High prevalence of perimenopausal depression was in most of the studies associated with previous episodes of mood disorders, which confirms the increased susceptibility to develop depression during menopause in women with recurrent depressive disorder (Avis et al., 1994; Hunter, 1990; Porter et al., 1996; Stone and Pearlstein, 1994).

Several hypotheses have been put forth to explain relationships between affective disorders and menopause. Some theories postulate the significance of psychosocial changes or personality problems in women in this phase of life (Stone and Pearlstein, 1994; Vanwesenbeeck et al., 2001). However, the primary role in women-specific mood disorders is attributed to decreased activity of estrogens in menopause transition (Birkhauser, 2002; Dennerstein, 1987) and its impact on cerebral blood flow (Maki and Resnick, 2000; Pines et al., 2002; Resnick et al., 1998; Schmidt and Rubinow, 1997) as well as on the function of different neurotransmitters, especially the serotonergic system (Fink et al., 1996; Lippert et al., 1996; Rubinow et al., 1998; Steiner and Pearlstein, 2000). The significance of disordered serotonergic function was confirmed indirectly by studies indicating the effectiveness of serotonergic medications in the treatment of menopausal depression (Goodnick et al., 2000).

Mild to moderate depressive states can be treated successfully by primary care practitioners and other non-psychiatrist physicians (Mulrow et al., 2000). However, most research has confirmed the high incidence of unrecognized depressive disorders among patients in primary care (Schwenk et al., 1996) and in gynecological practice (Marcus et al., 2003). Patients tend to disclose more depressive symptoms in self-report questionnaires than during clinical evaluation in direct contact with physicians (Leung et al., 1998; Zich et al., 1990). Therefore, using screening instruments could help to diagnose patients presenting with symptoms of clinical depression. Moreover, the screening procedure alone may increase awareness of the possibility of depression in patients seen by physicians who administer the questionnaire and may help in making early decisions to initiate appropriate treatment.

Studies on screening for depression in midlife women have not been performed in gynecological clinics in Poland. The specific aims of our study were to evaluate the feasibility of screening for depression by gynecolo- gists within the standard practice of their clinics, and to estimate the prevalence of depressive disorders in women 45-55 years of age visiting gynecological clinics in Poland.

\section{Patients and methods}

\section{Subjects}

The study was designed as a multicenter population study conducted in both public and private outpatient gynecological clinics in Poland. Gynecological clinics were selected from the official database of gynecological outpatient clinics held by the Ministry of Health and Social Care and the Polish Chamber of Physicians. The entire database includes 3624 public and 1633 private outpatient clinics. The final list of 120 clinics was drawn from the database using a computer-generated randomization process. One gynecologist from each randomized center was approached and invited to participate in the study. At each study site, the gynecologist recruited 20 consecutive female patients aged 45 to 55 years into the study. The described procedure was employed to ensure a representative sample of Polish midlife female patients recruited in gynecological out-patients clinics. The study took place from May to October 2001. One-hundred-and-twenty gynecologists and 40 consulting psychiatrists participated in the study. A total of 2400 women visiting gynecologists were approached and asked to participate in the study. After complete description of the study to the subjects, written informed consent was obtained.

\section{Procedures}

The study was conducted in two major phases. First, all consecutive female patients visiting gynecologists, regardless of nature of complaint or reason for the visit, were approached and informed about the study. Those women who agreed to participate were requested to complete the Polish version of the BDI (Beck et al., 1961; Parnowski and Jernajczyk, 1977) while in the waiting-room of the clinic. Next, during this visit, the gynecologist assessed the BDI score. Patients who scored 12 points or more on the BDI (the cut-off point for depression in Poland; (Parnowski and Jernajczyk, 1977) were evaluated by a gynecologist to confirm or rule out a preliminary diagnosis of depression. ICD-10 criteria for symptoms of Depressive Episode (WHO, 1992) were used. Gynecologists also obtained a detailed medical history for all patients. All women scoring 12 points or more on the BDI were then referred for a psychiatric consultation. All information was entered by gynecologists into a Clinical Record Form. In the second phase of the study, patients scoring 12 points or more on the BDI were referred to a psychiatric out-patient clinic at a nearest location recommended by the gynecologist. The patients were examined by a psychiatrist, who used the modified Polish version of MINI (Sheehan et al., 1998), a short-structured diagnostic interview based on the ICD-10 Classification that has been used to diagnose depressive disorders in primary care, psychiatric clinics as well as gynecological out-patient practices (Duburcq et al., 1999; Hsiao et al., 2002; Kouakam et al., 2002). The final diagnosis of an affective disorder was made by a psychiatrist based on clinical psychiatric examination. The psychiatrist also collected a history of previous 
episodes of psychiatric disorders and treatment received, and made a decision about the need for current psychiatric treatment (antidepressants or other medications) as well as a site for further treatment (psychiatric hospital, psychiatric out-patient clinic, primary care, gynecological clinic). All information regarding the diagnosis of a psychiatric disorder, resulting from use of MINI interview, and collected psychiatric history were entered into the Clinical Record Form. The study was initiated after the formal approval of the Bioethics Committee of the Medical University of Warsaw for all participating centers, and ethical principles of the Helsinki Declaration (updated in Edinburgh in 2000) were followed. The study was supported by an unrestricted research grant from Servier Polska and registered at the Central Register of Clinical Research.

\section{Analyses}

In the statistical analysis, basic descriptive analyses of all studied parameters were performed. Demographic and clinical data were compared between "high BDI" (12 points or more of the BDI score) and "low BDI" (less than 12 points on the BDI) groups using chi-square tests for categorical variables (with Yates's corrections, when appropriate), t-tests for independent samples for normally distributed continuous variables (with Bonferroni corrections), and Mann-Whitney tests for continuous variables when there was not a normal distribution (nonparametric comparisons). Two-tailed tests with a 5\% level of significance were used throughout the analyses. All analyses were conducted using SPSS-PC (Norusis, 1994).

In order to estimate the frequency of diagnosis of a depressive disorder in the entire studied population of women, approximation analysis using the Monte-Carlo method was performed. Computer software used techniques of random simulation to assess the probability of a diagnosis of depression occurring in the subgroup of patients who were not evaluated by psychiatrists. The group of patients that was diagnosed by the psychiatrists was divided into smaller groups according to 6 intervals of BDI scores $(12-15 ; 16-20 ; 21-25 ; 26-30 ; 31-35$; > 35). For each small group, the probability of a diagnosis of depression was calculated, and then values of that probability were applied to respective intervals of BDI scores in the group not diagnosed by psychiatrist. Finally, for the latter group, the total probability of a diagnosis of depression was calculated.

This method attempts to extrapolate the probability of diagnosis of depression to the women not evaluated by psychiatrist. Therefore, it is only an estimation of the likelihood of depres- sion found in these women, and may well over- or underestimate the real prevalence of depression in the whole study sample, so the results should be interpreted cautiously.

\section{Results}

Of the 2400 women asked to participate in the study, 2262 women $(94.3 \%) 45$ to 55 years of age agreed to be included in the study and filled out the BDI scale. The mean age for the study sample was $49.85 \pm 3.09$ years.

In the first phase of the study, 734 patients (32.5\%) achieved a score of 12 points or more on the BDI ("high BDI" group), and 1528 women (67.5\%) scored less than 12 points ("low BDI" group). The average BDI score was $21.4 \pm 19.0$ in the former group and $6.0 \pm 6.0$ in the latter $(\mathrm{p}<0.01)$. The mean ages in both groups were comparable.

Gynecologists who participated in the study reported that $38.2 \%$ of their patients with high BDI scores seemed to be depressed at the time of assessment. However, after careful verification of ICD-10 basic criteria for Depressive Episode, gynecologists found depressed mood in $62 \%$ of patients with high BDI scores, loss of interests and ability to feel pleasure in $55 \%$ of these patients, and loss of energy or fatigue in $68 \%$ of these subjects. Sixty-two percent of patients with high BDI scores (442 of 714) were assessed by gynecologists to have symptoms of depression according to ICD-10 criteria for Depressive Episode.

Current somatic complaints were the primary reason for the visit of 444 patients $(60.5 \%)$ in the high BDI group and of 500 women $(32.7 \%)$ in the low BDI group (Table 1). Among other reasons for the visit were: regular yearly gynecological assessment, cytological examination, a need for medication, and a need for a change in medication.

Most women in the high BDI group reported multiple menopausal complaints, as shown in Table 2. The most frequently described symptoms included: heart palpitations, night sweats, hot flashes, joint pains, vaginal

Table 1. Presenting problems of women aged $45-55$ years visiting gynecologists by low BDI scores (BDI $<12$ ) and high BDI scores (BDI score $\geq 12$ )

\begin{tabular}{llll}
\hline Main reason of the visit & $\begin{array}{l}\text { BDI }<12 \\
\mathrm{n}=1528 \\
\%\end{array}$ & $\begin{array}{l}\text { BDI } \geq 12 \\
\mathrm{n}=734 \\
\%\end{array}$ & $\mathrm{p}$ \\
\hline Control gynecological assessment & 80.6 & 76.0 & 0.02 \\
Current somatic complaints & 32.7 & 60.5 & $*$ \\
A need for medication or a need of change of medication taken & 30.3 & 21.7 & $*$ \\
Cytological examination & 8.0 & 6.2 & n.s. \\
\hline
\end{tabular}

Chi-square test, ${ }^{*} \mathrm{p}<0.01 ;$ n.s. - not significant. 
Table 2. Menopausal somatic symptoms in women enrolled in the study

\begin{tabular}{llll}
\hline Complaints reported & $\begin{array}{l}\text { BDI }<12 \\
\mathrm{n}=1528 \\
\%\end{array}$ & $\begin{array}{l}\text { BDI } \geq 12 \\
\mathrm{n}=734 \\
\%\end{array}$ & $\mathrm{p}$ \\
\hline Any menopausal symptom & 93.9 & 99.7 & $*$ \\
Heart palpitations & 33.4 & 64.7 & $*$ \\
Night sweats & 28.1 & 57.8 & $*$ \\
Hot flashes & 31.3 & 55.3 & $*$ \\
Joint pains & 35.3 & 56.4 & $*$ \\
Vaginal dryness or painfulness & 21.1 & 34.3 & $*$ \\
Skin atrophy & 16.0 & 25.5 & $*$ \\
Mammary gland atrophy & 12.8 & 15.5 & n.s. \\
\hline
\end{tabular}

Chi-square test; ${ }^{*} \mathrm{p}<0.01 ;$ n.s. - not significant.

dryness, skin atrophy. Women in the low BDI group reported such complaints significantly less frequently.

As can be seen in Table 3, women in the high BDI group had significantly more pregnancies than those in the low BDI group. There was also a significant difference in duration of menopausal symptoms: women with high BDI scores reported such symptoms lasting more than half a year longer than those with low BDI scores. The duration of hormone replacement therapy (HRT) as well as the time since the beginning of HRT to the relief of menopausal symptoms was not different between the two groups.

Gynecological history data are presented in Table 4. The high BDI group of patients reported symptoms of premenstrual syndrome, abortions and complications during pregnancy and the perinatal period more frequently than women with low BDI scores. Females with high BDI scores more often experienced depression during pregnancy, postpartum blues and postpartum depression or psychosis than women with low scores. There were no differences in the number of miscarriages or childbirths between the groups.

Patients in the high BDI group experienced more gynecological surgeries in the past. Among the surgical procedures, hysterectomy or mastectomy due to cancer was reported significantly more often by the women in the high BDI group, whereas females with low scores reported more dilation and curettage procedures. In the high BDI group, breast diseases were more often noted, among them fibrocystic mastopathy (benign breast proliferation $-25 \%$ ), non-malignant nodules $(20 \%)$, cystic breast disease (14\%) and breast cancer (8\%). There were no significant differences in the frequency of hormonal contraceptive treatment or the frequency of depressed mood associated with such therapy. More than half of the females in both groups received HRT. No differences were found between the number of women on HRT in each group or the type of hormonal medication administered. However, women in the low BDI group more often evaluated HRT as an effective therapy.

The most common medical disorders found in these patients are presented in Table 5. As can be seen from the table, hypertension, ischemic heart disease, hypothyroidism, other diseases of the thyroid gland (hyperthyroidism, non-toxic thyromegaly and thyroid nodules), and diabetes were the most frequently reported diseases. There were no differences between the two groups of women in the frequency of somatic disorders.

Patients with high BDI scores visited their gynecologists significantly more frequently during the year preceding the study (on average of 3 times a year compared with 2 times by patients with low BDI scores). As shown in Table 6, women with high BDI scores also reported difficult, stressful events (i.e., death of a close person, job loss, financial loss, family conflict, divorce, children's leaving, etc.) more frequently during the last 6 months prior to their current visit and confirmed either a diagnosis of depression in the past or previous psychiatric treatment. Almost 14\% of gynecologic patients aged 45-55 years who scored 12 points or more on the BDI were currently treated by psychiatrists at the time of the study. Females with high BDI scores also had significantly higher rates of family history of depression than patients without depressive symptoms. In addition, depression occurred more frequently in mothers $(47 \%)$ and sisters $(20 \%)$ of patients, while fathers and brothers rarely suffered from depression ( $8 \%$ and $4 \%$, respectively).

Table 3. Gynecological history of women with low and high BDI scores

\begin{tabular}{|c|c|c|c|c|c|c|c|}
\hline & \multicolumn{3}{|c|}{$\begin{array}{l}\text { BDI }<12 \\
n=1528\end{array}$} & \multicolumn{3}{|c|}{$\begin{array}{l}\mathrm{BDI} \geq 12 \\
\mathrm{n}=734\end{array}$} & \multirow[t]{2}{*}{$\mathrm{p}$} \\
\hline & mean & $\min -\max$ & median & mean & $\min -\max$ & median & \\
\hline Number of pregnancies & 2.2 & $0-10$ & 2 & 2.4 & $0-11$ & 2 & * \\
\hline Duration of climacteric symptoms (months) & 15.3 & $0-324$ & 6 & 21.6 & $0-144$ & 12 & * \\
\hline Duration of treatment with HRT (months) & 18.7 & $0-132$ & 12 & 17.7 & $1-96$ & 12 & n.s. \\
\hline Time to relieve climacteric symptoms (months) & 2.2 & $0-50$ & 2 & 2.5 & $0-72$ & 2 & n.s. \\
\hline
\end{tabular}

Mann-Whitney test; ${ }^{*} \mathrm{p}<0.01 ;$ n.s. - not significant. 
Table 4. Gynecological and obstetric history of women with low and high BDI scores

\begin{tabular}{|c|c|c|c|}
\hline & $\begin{array}{l}\mathrm{BDI}<12 \\
\mathrm{n}=1528 \\
\%\end{array}$ & $\begin{array}{l}\text { BDI } \geq 12 \\
\mathrm{n}=734 \\
\%\end{array}$ & $\mathrm{p}$ \\
\hline Premenstrual syndrome & 47.8 & 56.4 & * \\
\hline Miscarriages & 20.6 & 22.3 & n.s. \\
\hline Abortions & 9.2 & 12.7 & 0.02 \\
\hline Complications during pregnancies & 17.1 & 23.2 & $*$ \\
\hline Complications during perinatal period & 7.4 & 13.6 & * \\
\hline Mood disorder during perinatal period & 6.7 & 15.8 & * \\
\hline Symptoms of depression during pregnancy & 3.3 & 12.8 & * \\
\hline Postpartum blues & 12.5 & 23.6 & * \\
\hline Postpartum major depression & 2.3 & 10.3 & * \\
\hline Postpartum psychosis & 0.3 & 2.5 & * \\
\hline Gynecological surgery in the past & 44.4 & 54.1 & * \\
\hline Breast diseases in the past & 12.6 & 16.3 & $*$ \\
\hline Contraceptives use & 22.6 & 21.1 & n.s. \\
\hline Mood disorders after contraceptives & 9.6 & 15.5 & n.s. \\
\hline Hormone Replacement Therapy use & 57.8 & 56.5 & n.s. \\
\hline Relieve of climacteric symptoms with HRT treatment & 60.5 & 55.0 & 0.039 \\
\hline
\end{tabular}

Chi-square test, ${ }^{*} \mathrm{p}<0.01 ;$ n.s. - not significant.

Table 5. Co-occurring medical disorders in women with low and high BDI scores

\begin{tabular}{llll}
\hline Medical disorder & $\begin{array}{l}\text { BDI }<12 \\
\mathrm{n}=1528 \\
\%\end{array}$ & $\begin{array}{l}\text { BDI } \geq 12 \\
\mathrm{n}=734 \\
\%\end{array}$ & $\mathrm{p}$ \\
& 21.9 & 26.8 & n.s. \\
Hypertension & 7.0 & 10.4 & n.s. \\
Coronary heart disease & 2.2 & 1.9 & n.s. \\
Diabetes & 3.3 & 5.3 & n.s. \\
Hypothyroidism & 6.7 & 11.2 & n.s. \\
Other thyroid gland disease & & &
\end{tabular}

Chi-square test, n.s. - not significant.

Table 6. Psychiatric history of women with low and high BDI scores

\begin{tabular}{|c|c|c|c|}
\hline & $\begin{array}{l}\text { BDI }<12 \\
\mathrm{n}=1528 \\
\%\end{array}$ & $\begin{array}{l}\text { BDI } \geq 12 \\
\mathrm{n}=734 \\
\%\end{array}$ & $\mathrm{p}$ \\
\hline Stressful events in last 6 months ${ }^{\mathrm{a}}$ & 16.9 & 35.9 & * \\
\hline Diagnosis of depression in the past & 4.8 & 21.5 & * \\
\hline Psychiatric treatment in the past & 4.8 & 23.0 & * \\
\hline Current psychiatric treatment & 3.3 & 13.5 & * \\
\hline Family history of depression & 5.8 & 14.0 & * \\
\hline
\end{tabular}

Chi-square test, ${ }^{*} \mathrm{p}<0.01$.

${ }^{a}$ (e.g., death of a close person, job loss, financial loss, family conflict, divorce, children's leaving, etc.).

In the second phase of the study, of the 734 women with high BDI scores of 12 points or more who were referred to a psychiatrist, only 317 (43.2\%) came for a consultation, while 417 females $(56.8 \%)$ did not visit a consulting psychiatrist. BDI scores in both subgroups were significantly different $(23.6 \pm 9.0$ points for women who came for a consultation, and $19.7 \pm 7.2$ $(\mathrm{p}<0.01)$ for women who did not go to psychiatrist).

Psychiatrists diagnosed Depressive Episode (F32) in $33 \%$ of patients and Recurrent Depressive Disorder (F33) in 30\% of women who came in for a consultation. Dysthymia was diagnosed in $13 \%$ of patients. Almost one-fourth (24\%) of these women were not given a diagnosis of a depressive disorder, however, in total, a diagnosis of an affective disorder (F32-F34) was assigned to 195 of 317 women (61.5\%). Taking into account the 417 women who were not examined by psychiatrist, the total estimated probability of a diagnosis of depression occurring in women aged 45 to 55 years who scored 12 points or more on BDI was calculated as 0.567. Thus, 236 subjects might be assigned a diagnosis of depression among the 417 women who did not come to psychiatrist. Therefore, 431 patients (58.7\%) in the group of females who scored high on BDI were estimated to have a Depressive Disorder, which gives a proportion of $19.1 \%$ to the entire study population $(\mathrm{N}=2262)$.

Based on clinical examination, consulting psychiatrists recommended that 148 (76\%) of 195 women with a diagnosis of depression should be treated with antidepressant medication. Among those depressed females, $44 \%$ ought to be treated by psychiatrist, and $56 \%$ could be treated for depression by their gynecologist.

\section{Discussion}

The study showed that gynecologists in Poland are able to perform screening for depression effectively in 
outpatient settings. Gynecologists successfully screened and attempted to make preliminary diagnoses of depression using ICD-10 diagnostic criteria for most (94\%) of visiting patients aged 45-55 years. Verification of criteria for depressive episode by gynecologists revealed almost the same proportion of depression in the group with high BDI scores as assessed by psychiatrists. One could assume then, that gynecologists in Poland were able to more accurately diagnose depression according to ICD-10 criteria in their patients than physicians in other studies (Sartorius et al., 1993; Sartorius et al., 1996; Ustun and Sartorius, 1995). In the WHO study, primary-care practitioners diagnosed depression in only $2.8 \%$ of their patients while verification of the diagnosis with standardized tools revealed a three times higher prevalence of depression (8.7\%). However, gynecologists in our study made only preliminary diagnoses of depression and did not use validated diagnostic tools.

In the studied sample of midlife women, only $43 \%$ who were referred actually came for a psychiatric consultation. Presumably, women with more severe symptoms of depression came for evaluation by psychiatrists, which was confirmed by the higher mean BDI score in this subgroup. Most of those women who did not come for psychiatric evaluation showed less prominent depressive symptomatology (had lower BDI scores). The decision to visit a psychiatrist is very difficult in Poland, because such a visit is still perceived as very stigmatizing in Polish culture, and thus most of the women in this study did not come for assessment in psychiatric clinics. Since many cases of depression in primary care remain undetected (Sartorius et al., 1996; Simon and VonKorff, 1995), using a screening procedure for depression administered by gynecologists could benefit at least those outpatients with undiagnosed depression who visit gynecological clinics.

Results of this study estimated that about $19 \%$ of women aged 45 to 55 years visiting gynecological clinics in Poland may suffer from depressive disorders. Therefore, it can be assumed that one in five women at that age who visit a gynecologist may experience symptoms of depression. Compared with findings from studies in similar populations of women, results of this study indicate that Polish women may have lower levels of depressive symptoms during menopause transition than women in Western countries (Anderson et al., 1987; Hay et al., 1994; Schmidt et al., 1997).

However, it is important to emphasize that, since more than fifty percent of patients did not go for their referral for a psychiatric consultation to verify a diagnosis of depression, the proportion of females suffering from depression in our study was estimated using a statistical approximation method. This methodology may well under- or overestimate the real prevalence of the disorder. We assumed that using BDI scores as intervals to assess probability of depression among those women who did or did not go for a psychiatric consultation is the most reliable way of estimating total prevalence. However, we did not evaluate depression in patients who scored fewer than 12 points on the BDI, assuming that the high positive predictive value of BDI as a screening instrument justifies not sending those patients for further assessment. Therefore, we do not have an estimate of prevalence of depression in this group. Moreover, extrapolating the prevalence of depression from the group who visited psychiatrists (constituting the most depressed patients based on their high BDI scores) to the whole population of women aged 45-55 years visiting gynecologists may lead to overestimating the prevalence of depression in the entire study sample. Therefore, the generalizability of our results is very limited and should be interpreted cautiously.

Women who scored high on the BDI visited their gynecologists more frequently during previous year than women with lower BDI scores. This finding corresponds with results of other studies of primary-care patients with and without symptoms of depression (Anderson et al., 1987; Katon, 1987). In our study, females with higher BDI scores not only experienced menopausal symptoms about six months earlier than women with low BDI scores, but they also reported these symptoms significantly more frequently. These symptoms might have led to their more intensive use of health services in the past. Presumably, appropriate treatment of depression could decrease costs of health-care services utilization in this group of patients.

Results of our study suggest that a thorough gynecological history is critical to assess the possibility of depression in the period of menopause transition (Hay et al., 1994; McKinlay et al., 1987; Porter et al., 1996; Schmidt et al., 1997). High risk of depression may be related to prior events such as premenstrual mood disorders, greater number of pregnancies and abortions, depressive episodes during pregnancy or postpartum depression, stressful life events, familial burden of depression, and co-occurring somatic diseases. Women with depressive symptomatology in our sample experienced more difficult, traumatic life events during the six months preceding the current visit. This finding may endorse the extant association between mood disorders 
and adverse life events (McKinlay et al., 1987), but it may also result from a memory bias, since depressed patients tend to remember and report more negative events and stressful symptoms from the past than non-depressed subjects. Recording stressful events as well as most of symptoms in this study, although collected by gynecologists, relied on self-reports of these women. Such retrospective data could lead to a significant recall bias, which should be considered as one of the important limitations of our study.

Our study agrees with previous findings of possible relationships between premenstrual and perinatal mood disorders with a subsequent risk of depression in the period of menopause transition (Hay et al., 1994; McKinlay et al., 1987; Porter et al., 1996; Rubinow et al., 1998; Schmidt et al., 1997). Subjects with high BDI scores also more frequently reported a family history of depression, especially among female relatives. This finding may indicate a potential genetic basis for menopausal mood disorders, but again, it is based on self-report data.

The studied sample entailed patients with a variety of pre-existing medical disorders (e.g., thyroid disease) that could produce both somatic and affective symptoms reported by assessed women. Also, taking HRT by the most of patients could contribute to the differences in experiencing some somatic and emotional symptoms in low and high BDI groups, and thus, even could influence BDI scores. However, after stratification of the sample by HRT treatment as well as presence of preexisting medical disorders, all differences between the groups remained significant, which indicates that the effect of these potential confounders is minimal.

Research has thus far recognized possible associations between hormonal and emotional disturbances in the menopausal transition (Nicol-Smith, 1996; Rubinow et al., 1998; Schmidt et al., 1997). In our study, female patients with low or no depressive symptomatology (low BDI group) evaluated the HRT therapy as more effective and less frequently reported menopausal symptoms than females with high BDI scores. This finding might suggest that HRT not only alleviates somatic manifestations of menopause, but also improves depressed mood at least in some women. However, most clinical trials showed only a modest influence of estrogens on symptoms of depression and they did not confirm direct antidepressant effects of hormonal treatment of menopause (Stoppe and Doren, 2002).

This study estimated that one-fifth of women aged 45-55 years who visit gynecologists in Poland may suf- fer from depression and presumably may seek help primarily from gynecological clinics. According to the opinions of the consulting psychiatrists, about $45 \%$ of women with a diagnosis of depression had symptoms severe enough to require further treatment by a psychiatrist, while more than half of evaluated women with depression could be treated by antidepressant therapy prescribed by their gynecologists. This group of patients needs special attention and presents a particular challenge for the treating physician. According to our results, midlife women with more prominent depressive symptomatology not only may have had more psychiatric, somatic or gynecological problems in the past, but also, consequently, may report more menopausal symptoms during more frequent visits to gynecological clinics.

The main limitation of our study derives from the retrospective nature of the self-reported data which might produce selective recall bias due to depression. Also, the studied sample was not homogenous and covered a broad range of women in respect to their menopause transition (i.e., premenopausal, perimenopausal and postmenopausal), which makes it difficult to link depressive symptoms with menopausal status. Moreover, we lacked data on hormonal function of these patients. In addition, assessment of the prevalence of depressive disorders in these women is limited, since there is no comparable epidemiological data on the prevalence of depression in other age groups of women in Poland, especially those attending outpatient gynecological clinics. Our results are then limited only to this particular group of patients. Using the BDI as an indicator of depression in menopausal women also has some restrictions. This instrument is a screening tool, and measures severity of symptoms typical for depression. However, most women in menopause transition report somatic and emotional symptoms which may not be directly associated with depression, but may contribute to higher BDI scores. In our sample, $38 \%$ of patients with high BDI scores had no confirmed diagnosis of depression.

Our study showed that gynecologists can effectively provide screening for depressive disorders and, in addition, can approach diagnosing depression. Given the fact that many women with symptoms of depression often do not seek treatment from a psychiatrist, gynecologists and other primary care physicians may be important sources of care for these women. Gynecologists should be encouraged to use simple screening tools (e.g., BDI) in high-risk patients to identify those women who require diagnostic evaluation and treatment for depression 
(Concin et al., 2002; USPSTF, 2002). The low proportion of depressive patients who came to psychiatrists for consultation may indicate a fear of stigmatization and this fact supports the need for intensive educational programs designated not only for physicians of different specialities, but also for women and their families.

\section{References}

Anderson E, Hamburger S, Liu JH, Rebar RW (1987) Characteristics of menopausal women seeking assistance. Am J Obstet Gynecol 156: 428-433.

Avis NE, Brambilla D, McKinlay SM, Vass K (1994) A longitudinal analysis of the association between menopause and depression. Results from the Massachusetts Women's Health Study. Ann Epidemiol 4: 214-220.

Bailey JW, Cohen LS (1999) Prevalence of mood and anxiety disorders in women who seek treatment for premenstrual syndrome. J Womens Health Gend Based Med 8: 1181-1184.

Ballinger CB (1990) Psychiatric aspects of the menopause. Br J Psychiatry 156: 773-787.

Bebbington PE, Dunn G, Jenkins R, Lewis G, Brugha T, Farrell M, Meltzer H (1998) The influence of age and sex on the prevalence of depressive conditions: report from the National Survey of Psychiatric Morbidity. Psychol Med 28: 9-19.

Beck A, Ward C, Mendelson M, Mock J, Erbaugh J (1961) An inventory for measuring depression. Arch Gen Psychiatry 4: 561-571.

Birkhauser M (2002) Depression, menopause and estrogens: is there a correlation? Maturitas 41 Suppl 1: S3-S8.

Bosworth HB, Bastian LA, Kuchibhatla MN, Steffens DC, McBride CM, Skinner CS, Rimer BK, Siegler IC (2001) Depressive symptoms, menopausal status, and climacteric symptoms in women at midlife. Psychosom Med 63: 603-608.

Braverman J, Roux JF (1978) Screening for the patient at risk for postpartum depression. Obstet Gynecol 52: 731-736.

Cathebras P, Mosnier C, Levy M, Bouchou K, Rousset H (1994) [Screening for depression in patients with medical hospitalization. Comparison of two self-evaluation scales and clinical assessment with a structured questionnaire]. Encephale 20: 311-317.

Concin H, Ulmer H, Hefler L (2002) Mental well-being in 5000 women participating in the 'Women-Plus' preventive medicine program. Maturitas 41 Suppl 1: S9-S12.

Cooper PJ, Murray L (1998) Postnatal depression. BMJ 316: 1884-1886.

Coyne JC, Fechner-Bates S, Schwenk TL (1994) Prevalence, nature, and comorbidity of depressive disorders in primary care. Gen Hosp Psychiatry 16: 267-276.

Dennerstein L (1987) Depression in the menopause. Obstet Gynecol Clin North Am 14: 33-48.

Dennerstein L, Lehert P, Burger H, Dudley E (1999) Mood and the menopausal transition. J Nerv Ment Dis 187: 685-691.

Duburcq A, Blin P, Charpak Y, Blachier C, Allicar MP, Bouhassira M, Hergueta T, Lecrubier Y (1999) Use of a structured diagnostic interview to identify depressive episodes in an epidemiologic study: a posteriori internal validation. Rev Epidemiol Sante Publique 47: 455-463.

Fink G, Sumner BE, Rosie R, Grace O, Quinn JP (1996) Estrogen control of central neurotransmission: effect on mood, mental state, and memory. Cell Mol Neurobiol 16: 325-344.

Goodnick PJ, Chaudry T, Artadi J, Arcey S (2000) Women's issues in mood disorders. Expert Opin Pharmacother 1: 903-916.

Hay AG, Bancroft J, Johnstone EC (1994) Affective symptoms in women attending a menopause clinic. Br J Psychiatry 164: 513-516.
Holcomb WL Jr, Stone LS, Lustman PJ, Gavard JA, Mostello DJ (1996) Screening for depression in pregnancy: characteristics of the Beck Depression Inventory. Obstet Gynecol 88: 1021-1025.

Hsiao MC, Liu CY, Chen KC, Hsieh TT (2002) Characteristics of women using a mental health clinic in a gynecologic out-patient setting. Psychiatry Clin Neurosci 56: 459-463.

Hunter MS (1990) Psychological and somatic experience of the menopause: a prospective study [corrected]. Psychosom Med 52: 357-367.

Katon W (1987) The epidemiology of depression in medical care. Int J Psychiatry Med 17: 93-112.

Kaufert PA, Gilbert P, Tate R (1992) The Manitoba Project: a reexamination of the link between menopause and depression. Maturitas 14: 143-155.

Kessler RC, McGonagle KA, Zhao S, Nelson CB, Hughes M, Eshleman S, Wittchen HU, Kendler KS (1994) Lifetime and 12-month prevalence of DSM-III-R psychiatric disorders in the United States. Results from the National Comorbidity Survey. Arch Gen Psychiatry 51: 8-19.

Kouakam C, Lacroix D, Klug D, Baux P, Marquie C, Kacet S (2002) Prevalence and prognostic significance of psychiatric disorders in patients evaluated for recurrent unexplained syncope. Am J Cardiol 89: $530-535$.

Leung KK, Lue BH, Lee MB, Tang LY (1998) Screening of depression in patients with chronic medical diseases in a primary care setting. Fam Pract 15: 67-75.

Lippert TH, Filshie M, Muck AO, Seeger H, Zwirner M (1996) Serotonin metabolite excretion after postmenopausal estradiol therapy. Maturitas 24: 37-41.

Maki PM, Resnick SM (2000) Longitudinal effects of estrogen replacement therapy on PET cerebral blood flow and cognition. Neurobiol Aging 21: 373-383.

Marcus S, Flynn H, Blow F, Barry K (2003) Depressive symptoms among pregnant women screened in obstetrics settings. J Womens Health 12: 373-380.

Matthews KA, Wing RR, Kuller LH, Meilahn EN, Plantinga P (1994) Influence of the perimenopause on cardiovascular risk factors and symptoms of middle-aged healthy women. Arch Intern Med 154: 2349-2355.

McKinlay JB, McKinlay SM, Brambilla D (1987) The relative contributions of endocrine changes and social circumstances to depression in mid-aged women. J Health Soc Behav 28: 345-363.

Mulrow CD, Williams JW Jr, Chiquette E, Aguilar C, Hitchcock-Noel P, Lee S, Cornell J, Stamm K (2000) Efficacy of newer medications for treating depression in primary care patients. Am J Med 108: 54-64.

Nicol-Smith L (1996) Causality, menopause, and depression: a critical review of the literature. BMJ 313: 1229-1232.

Norusis MJ (1994) SPSS for Windows: Base System User's Guide and Advanced Statistics, SPSS, Inc., Chicago.

Parnowski T, Jernajczyk W (1977) Beck's depression inventory in the rating of mood in normal subjects and in patients with affective disturbances. Psychiatr Pol 11: 417-421.

Pearlstein T, Rosen K, Stone AB (1997) Mood disorders and menopause. Endocrinol Metab Clin North Am 26: 279-294.

Pines A, Bornstein NM, Shapira I (2002) Menopause and ischaemic stroke: basic, clinical and epidemiological considerations. The role of hormone replacement. Hum Reprod Update 8: 161-168.

Porter M, Penney GC, Russell D, Russell E, Templeton A (1996) A population based survey of women's experience of the menopause. $\mathrm{Br}$ J Obstet Gynaecol 103: 1025-1028.

Resnick SM, Maki PM, Golski S, Kraut MA, Zonderman AB (1998) Effects of estrogen replacement therapy on PET cerebral blood flow and neuropsychological performance. Horm Behav 34: 171-182. 
Robins L, Rieger D (1991) Psychiatric Disorders in America: The Epidemiologic Catchment Area Study, New York Free Press, New York.

Rubinow DR, Schmidt PJ, Roca CA (1998) Estrogen-serotonin interactions: implications for affective regulation. Biol Psychiatry 44: 839-850.

Sartorius N, Ustun TB, Costa e Silva JA, Goldberg D, Lecrubier Y, Ormel J, Von Korff M, Wittchen HU (1993) An international study of psychological problems in primary care. Preliminary report from the World Health Organization Collaborative Project on 'Psychological Problems in General Health Care'. Arch Gen Psychiatry 50: 819-824.

Sartorius N, Ustun TB, Lecrubier Y, Wittchen HU (1996) Depression comorbid with anxiety: results from the WHO study on psychological disorders in primary health care. Br J Psychiatry Suppl: 38-43.

Schmidt PJ, Rubinow DR (1997) Neuroregulatory role of gonadal steroids in humans. Psychopharmacol Bull 33: 219-220.

Schmidt PJ, Roca CA, Bloch M, Rubinow DR (1997) The perimenopause and affective disorders. Semin Reprod Endocrinol 15: 91-100.

Schwenk TL, Coyne JC, Fechner-Bates S (1996) Differences between detected and undetected patients in primary care and depressed psychiatric patients. Gen Hosp Psychiatry 18: 407-415.

Sheehan DV, Lecrubier Y, Sheehan KH, Amorim P, Janavs J, Weiller E, Hergueta T, Baker R, Dunbar GC (1998) The Mini-International Neuropsychiatric Interview (M.I.N.I.): the development and validation of a structured diagnostic psychiatric interview for DSM-IV and ICD-10. J Clin Psychiatry 59 Suppl 20: 22-33, 34-57.

Simon GE, VonKorff M (1995) Recognition, management, and outcomes of depression in primary care. Arch Fam Med 4: 99-105.

Steiner M (1992) Female-specific mood disorders. Clin Obstet Gynecol 35: 599-611.

Steiner M (1998) Perinatal mood disorders: position paper. Psychopharmacol Bull 34: 301-306.
Steiner M, Pearlstein T (2000) Premenstrual dysphoria and the serotonin system: pathophysiology and treatment. J Clin Psychiatry 61 Suppl 12: $17-21$.

Steiner M, Yonkers K (1998) Depression in women, Martin Dunitz, London.

Stephenson-Cino P, Steiner M, Krames L, Ryan EB, Huxley G (1992) Depression in elderly persons and its correlates in family practice: a Canadian study. Psychol Rep 70: 359-368.

Stone AB, Pearlstein TB (1994) Evaluation and treatment of changes in mood, sleep, and sexual functioning associated with menopause. Obstet Gynecol Clin North Am 21: 391-403.

Stoppe G, Doren M (2002) Critical appraisal of effects of estrogen replacement therapy on symptoms of depressed mood. Arch Womens Ment Health 5: 39-47.

U.S. Preventive Services Task Force, USPSTF (2002) Screening for depression: recommendations and rationale. Ann Intern Med 136: 760-764.

Ustun TB, Sartorius N (1995) Mental Illness in General Health Care: An International Study. Wiley, London.

Vanwesenbeeck I, Vennix P, van de Wiel H (2001) 'Menopausal symptoms': associations with menopausal status and psychosocial factors. J Psychosom Obstet Gynaecol 22: 149-158.

World Helath Organization, WHO (1992) The ICD-10 Classification of Mental and Behavioral Disorders. Clinical descriptions and diagnostic guidelines, WHO, Geneva.

Zich JM, Attkisson CC, Greenfield TK (1990) Screening for depression in primary care clinics: the CES-D and the BDI. Int J Psychiatry Med 20: 259-277.

Correspondence: Marcin Wojnar, MD, PhD, University of Michigan Addiction Research Center, 400 E. Eisenhower Pkwy, Suite 2A. Ann Arbor, MI 48108-3318, U.S.A.; e-mail: mwojnar@umich.edu 